\title{
sala \\ de

\section{BIOENSAIO COMO MÉTODO DE APRENDIZAGEM ALIADO À TEORIA EM BIOLOGIA NO ENSINO MÉDIO}

\author{
BIOASSAY AS A LEARNING METHOD ALLIED TO THEORY IN BIOLOGY IN MIDDLE SCHOOL \\ Elenice Monte Alvarenga \\ Instituto Federal de Educação Ciência e Tecnologia do Piauí (IFPI) \\ Elenice_ma@hotmail.com \\ Paulo Sérgio de Araujo Souza \\ psergio.araujosouza@gmail.com \\ Samara Maria Gonçalves Carneiro \\ sam.goncalves@hotmail.com
}

\begin{abstract}
Resumo: as atividades práticas podem ser um grande instrumento para melhorar o ensino-aprendizagem possibilitando uma melhor compreensão dos assuntos abordados. Assim, objetivou-se o uso de bioensaios como proposta de ensino aliada à teoria em Biologia, em turmas de Ensino Médio Integrado. Para isso, realizouse: aplicação de questionários em duas turmas de segundos anos, de modo a se avaliar a aprendizagem; realização de experimento (bioensaio) em aula; e, por fim, reaplicação do questionário da primeira etapa, de modo que as últimas etapas serviram como instrumento de avaliação da aprendizagem dos discentes. Pôde-se observar a importância das atividades práticas para o aprendizado, em que a maior parte dos alunos afirmam que aprendem melhor com a utilização de aulas práticas como método complementar às aulas expositivas e demonstrativas, contribuindo diretamente para o processo de ensino-aprendizagem.
\end{abstract}

Palavras-chave: Bioensaios. Práticas. Aprendizagem.

\begin{abstract}
: practical activities can be a great tool to improve teaching-learning, enabling a better understanding of the subjects covered. The aim was to use bioassays as a teaching proposal combined with the theory in Biology, in integrated high school classes. For this, questionnaires were applied in two groups of second years, in order to assess learning; conducting an experiment (bioassay) in class; and, finally, the questionnaire of the first stage was reapplied, so that the last stages served as an instrument for assessing students' learning. It is possible to observe the importance of practical activities for learning, where most students affirm that they learn better with the use of practical classes as a complementary method to the expository and demonstrative classes, contributing directly to the teaching-learning process.
\end{abstract}

Keyboards: Bioassays. Practices. Learning.

\section{INTRODUÇÃO}

A educação está no centro de discussões acaloradas nos últimos tempos, com isso vem se buscando alternativas para melhorar a aprendizagem, como aquelas centradas no aspecto construtivista, uma vez que a relação entre prática e teoria pode tornar o aluno um ser mais ativo, de modo a estimulálo a um despertar para novos conhecimentos (MACHADO; GOMES; SANTOS, 2018). Nesse sentido, a realização de experimentos em Ciências Naturais pode se mostrar como uma magnífica ferramenta para que o aluno participe da experimentação e, com isso, da construção concreta da aprendizagem, 


\section{sala \\ de $\oplus$ em \\ aula foco}

-REVISTA ELETRÔNICA

além de poder estabelecer a dinâmica e indissociável relação entre teoria e prática.

As atividades experimentais foram inseridas nas escolas devido à forte influência de trabalhos desenvolvidos nas universidades, cujo objetivo era o de melhorar a aprendizagem do conhecimento científico por meio da aplicação do que foi aprendido (GALIAZZI et al., 2001; LEAL; MENDES SOBRINHO, 2008). Pode-se dizer, a partir disso, que as práticas pedagógicas devem fazer com que o aluno relacione os conhecimentos já existentes com as experiências do seu cotidiano e o conhecimento acadêmico e científico produzido nos espaços escolares. Nesse sentido, a aprendizagem ocorrerá por meio do que o aluno já sabe, ou seja, a construção do conhecimento dependerá dos conhecimentos já adquiridos. Desta forma, o resultado final do processo de aprendizagem é também diferente para cada estudante (FREIRE, 2015).

As atividades práticas podem ser um grande passo para melhorar o ensino-aprendizagem possibilitando uma melhor compreensão dos assuntos abordados. Dada a importância das aulas práticas para o ensino de Biologia, é importante a realização de estudos que esclareçam a realidade dessa abordagem dentro do cotidiano escolar.

É importante observar, também, que a abordagem prática não pode ser totalmente dissociada da teoria, pois ambas se complementam, cada uma apresentando sua função no processo de ensinoaprendizagem. Enquanto as teorias organizam o pensamento, relacionando fatos, auxiliando-nos na leitura e compreensão da realidade que ela trata, as técnicas metodológicas práticas ajudam na organização dos dados dessa realidade. Assim, teoria e prática constituem diferentes aspectos de um mesmo processo de produção de conhecimento (VENTURI, 2012; SANTOS; COLOMBO JÚNIOR, 2018).

Para que o ensino de Ciências e Biologia seja eficaz, o professor tem o desafio de levar em consideração o relacionamento dos alunos com o mundo natural e seus componentes. Daí que a falta de sentido da ciência apresentada na escola acontece por ser esta ministrada de forma metódica, distante dos interesses dos estudantes e, ainda, pelo fato de existir a fragmentação dos conteúdos, ou seja, nem sempre um assunto dá suporte ao outro, tornando difícil a sua compreensão (ORNELLAS, 2013; ANDRADE et al., 2018). 


\section{sala \\ de $\oplus$ em \\ aula foco}

REVISTA ELETRÔNICA

ISSN 2316-7297

Neste sentido, com este trabalho objetiva-se analisar e discutir a importância das aulas experimentais aliadas aos conteúdos teóricos de Biologia em turmas do Ensino Médio. Para isso, buscou-se estabelecer conexões entre o conteúdo teórico aplicado na sala de aula pelos docentes responsáveis pelas disciplinas e as aulas práticas realizadas em laboratório, e comparar o rendimento da aprendizagem, em conteúdo específico da disciplina de Biologia, entre os alunos que tiveram apenas aulas teóricas e alunos que tiveram aulas teóricas e práticas.

\section{METODOLOGIA}

Este trabalho foi realizado no Instituto Federal de Educação, Ciência e Tecnologia do Piauí (IFPI) campus Cocal, com alunos dos segundos anos de cursos técnicos integrados ao médio em Agricultura e Administração. A primeira etapa deste estudo constituiu-se na aplicação de um questionário, definido como pré-teste, no qual o mesmo foi realizado com 23 alunos do curso de Agricultura e com 27 do curso de Administração, totalizando 50 discentes. Nesta etapa, avaliou-se o nível de aprendizagem dos estudantes em relação aos conteúdos previamente estudados em Biologia, como Reino Animal e Ecologia, apenas por meio de estratégias teóricas de ensino. Em uma segunda etapa foi realizada uma aula prática, com a turma de Administração, em que 28 alunos participaram de atividades práticas em laboratório, com o uso de bioensaios envolvendo pesticidas.

O bioensaio realizado envolveu indivíduos da espécie Artemia salina (pequenos crustáceos) e consistiu na eclosão dos indivíduos encistados em água do mar artificial. Após isso, os indivíduos (náupilos na fase II ou III) foram expostos durante 24 ou 48 horas a concentrações crescentes de pesticida químico, de modo a se demonstrar a toxicidade do pesticida e observar aspectos do ciclo de vida do organismo.

Após isso, na terceira etapa do trabalho foi realizada a aplicação do pós-teste, que consistia na reaplicação do questionário inicial (primeira etapa), de modo a se comparar o rendimento obtido com e sem a utilização de estratégia prática de ensino. A análise dos dados foi feita no software Microsoft Excel ${ }^{\circledR}$.

\section{RESULTADOS E DISCUSSÃO}

\subsection{Resultados de avaliação de aprendizagem pré-realização de aula prática}




\section{sala \\ de $\oplus$ em \\ aula foco}

-REVISTA ELETRONNICA

Com a aplicação inicial do instrumento de coleta de dados, verificou-se que os alunos, quando questionados sobre as modalidades didáticas a que preferiam ter acesso na disciplina de Biologia, afirmaram que preferiam aulas expositivas (4\% dos alunos de Agricultura e $6 \%$ dos alunos da Administração); já $12 \%$ dos alunos de Agricultura e 14\% dos alunos de Administração preferiam aulas demonstrativas, enquanto $28 \%$ dos alunos de Agricultura e $34 \%$ dos alunos de Administração preferiam aulas práticas (Tabela 01).

Tabela 01 - Opinião dos alunos acerca da preferência em relação à aulas práticas, expositivas e demonstrativas na disciplina de Biologia no IFPI campus Cocal.

\begin{tabular}{|l|c|c|c|c|}
\hline & $\begin{array}{c}\text { Alunos do ensino médio integrado } \\
\text { ao técnico em administração }\end{array}$ & $\%$ & $\begin{array}{c}\text { Alunos do ensino médio } \\
\text { integrado ao técnico em } \\
\text { agricultura }\end{array}$ & $\%$ \\
\hline $\begin{array}{l}\text { Alunos que preferem } \\
\text { aulas expositivas. }\end{array}$ & 3 & 6 & 2 & 4 \\
\hline $\begin{array}{l}\text { Alunos que preferem } \\
\text { aulas demonstrativas. }\end{array}$ & 7 & 14 & 6 & 12 \\
\hline $\begin{array}{l}\text { Alunos que preferem } \\
\text { aulas práticas. }\end{array}$ & 17 & 34 & 14 & 28 \\
\hline
\end{tabular}

Fonte: Autor

Segundo Ascher (1966 apud KRASILCHICK, 2004), as modalidades didáticas podem ser classificadas em diversos critérios. Podem ser agrupadas de acordo com as atividades que os professores desenvolvem, tais como: falar (aulas expositivas), realizar discussões (fazer com que o aluno participe de debates, desenvolva seu lado crítico), fazer simulações (estimular a capacidade de o aluno envolver-se em algo que está sendo simulado), aulas práticas (procuram instigar o lado investigativo, deixar o aluno agir na busca pelas respostas), jogos (que trabalham o raciocínio, entre outras capacidades cognitivas), projetos e demonstrações (por meio de filmes, slides, que ajudam na construção da imagem, facilitando a interpretação e assimilação das informações). Nesse sentido, os estudantes participantes do estudo preferem a abordagem educativa com utilização de aulas práticas, facilitando o processo de aprendizagem.

Quanto à frequência das aulas práticas realizadas pelos professores, $4 \%$ dos alunos de Agricultura e 20\% dos alunos de Administração responderam que os professores não realizam aulas práticas; $4 \%$ dos alunos de Agricultura e 4\% dos alunos de Administração responderam que eles realizam aulas práticas 


\section{sala \\ de \\ aula

com frequência; 38\% dos alunos de Agricultura e 30\% dos alunos de Administração responderam que raramente realizam as aulas práticas associadas à abordagem teórica dos conteúdos (Tabela 02).

Tabela 02 - Frequência de aulas práticas realizadas pelos professores do IFPI campus Cocal

\begin{tabular}{|l|c|c|c|c|}
\hline & $\begin{array}{c}\text { Alunos do ensino médio } \\
\text { integrado ao técnico em } \\
\text { administração. }\end{array}$ & $\%$ & $\begin{array}{c}\text { Alunos do ensino médio integrado } \\
\text { ao técnico em agricultura }\end{array}$ & $\%$ \\
\hline $\begin{array}{l}\text { Não realizam aulas práticas } \\
\text { com frequência }\end{array}$ & 2 & 20 & 10 & 4 \\
\hline Realizam aulas práticas & 2 & 4 & 2 & 4 \\
\hline $\begin{array}{l}\text { Raramente realizam aulas } \\
\text { práticas }\end{array}$ & 19 & 30 & 15 & 38 \\
\hline
\end{tabular}

Fonte: Autor

Ao serem questionados sobre a importância das aulas práticas, 2\% dos alunos de Agricultura e 2\% dos alunos de Administração responderam que acreditam não ter muita relevância; 44\% dos alunos de Agricultura e 52\% dos alunos de Administração responderam que acreditam ser importante esta forma de abordagem dos conteúdos (Tabela 03).

Tabela 03 - Importância de aulas práticas para os alunos do ensino médio do IFPI campus Cocal

\begin{tabular}{|l|c|c|c|c|}
\hline & $\begin{array}{c}\text { Alunos do ensino médio integrado } \\
\text { ao técnico em administração }\end{array}$ & $\%$ & $\begin{array}{c}\text { Alunos do ensino médio integrado } \\
\text { ao técnico em agricultura }\end{array}$ & \begin{tabular}{c}
$\%$ \\
\hline $\begin{array}{l}\text { Acreditam que a abordagem } \\
\text { prática é relevante }\end{array}$
\end{tabular} \\
\hline $\begin{array}{l}\text { Acreditam que a abordagem } \\
\text { prática não é relevante }\end{array}$ & 1 & 2 & 1 & 2 \\
\hline
\end{tabular}

Fonte: Autor

As aulas práticas no ambiente de laboratório podem estimular a curiosidade e, por conseguinte, o interesse do aluno, visto que a estrutura das mesmas pode facilitar, dentre outros fatores, a observação de fenômenos estudados em aulas teóricas. O uso deste ambiente também é satisfatório quando as experiências em laboratório estão situadas em um contexto histórico-tecnológico, aliadas com o aprendizado do conteúdo de forma que o conhecimento empírico seja testado e argumentado para, enfim, acontecer a construção de ideias. Além do mais, nessas aulas os alunos têm a chance de interagir com as montagens de instrumentos específicos com as quais normalmente eles não têm contato em um ambiente com um caráter mais informal do que o ambiente da sala de aula (PIRES; PEIXOTO; OLIVEIRA, 2015; BORTOLUZZI; COUTINHO, 2018). 


\section{sala \\ de $\oplus$ em \\ aula foco}

-REVISTA ELETRÔNICA

Ao serem indagados sobre quais conteúdos seriam mais bem compreendidos com o auxílio das aulas experimentais, houve muita diversidade nas respostas, de modo que os alunos de Agricultura optaram pelos seguintes temas: plantas (2\%), citologia (8\%), doenças (4\%), bioquímica (2\%), corpo humano (12\%), seres vivos (4\%), genética (4\%). Os alunos de Administração optaram pelos temas: plantas (2\%), citologia (8\%), ácidos nucleicos (10\%).

Quando perguntados sobre quantas práticas são realizadas em média por semestre pelos professores, 24\% dos alunos de Agricultura e 50\% dos alunos de Administração responderam que apenas se realiza de 0 a 1 aula prática por semestre; 18\% dos alunos de Agricultura e 16\% dos alunos de Administração responderam que, em média, realiza-se de 1 a 2 aulas práticas; $4 \%$ dos alunos de Agricultura e $2 \%$ dos alunos de Administração responderam que são realizadas de 2 a 4 aulas práticas por semestre.

A utilização da abordagem prática é fundamental para desenvolver diversas habilidades, aguçando a curiosidade e a busca por respostas. O domínio do conhecimento científico é refletido na vida cotidiana dos alunos. Porém, mesmo diante de estudos que comprovam a relevância dessas metodologias, a realidade nas escolas públicas é outra. Estudos no país apontam experiências isoladas ou direções fragmentadas, não existindo uma teoria fundamentada sobre o ensino prático e, além disso, essa não está prevista no plano de nenhuma disciplina, não sendo, portanto, obrigatória sua realização (CHASSOT, 2003).

Os alunos também foram questionados se a compressão de um assunto melhorou com a observação de uma aula experimental e, de acordo com os resultados obtidos, $4 \%$ dos alunos de Agricultura e $2 \%$ dos alunos de Administração responderam que não, enquanto 40\% dos alunos de Agricultura e 50\% dos alunos de Administração responderam que sim.

Ao serem questionados sobre se a falta de aulas práticas aliadas aos conteúdos estudados com abordagem teórica poderia comprometer os processos de ensino e aprendizagem, $12 \%$ dos alunos de Agricultura e $20 \%$ dos alunos de Administração responderam que sim, uma vez que estes processos seriam completamente prejudicados, enquanto $34 \%$ dos alunos de Agricultura e $34 \%$ dos alunos de Administração responderam que seriam prejudicados apenas parcialmente. 


\section{sala \\ de $\oplus$ em \\ aula foco}

- REVISTA ELETRÔNICA

Aos alunos também foi questionado em que aspectos as aulas experimentais contribuiriam para o seu aprendizado. Nesse sentido, 6\% dos alunos de Agricultura e $20 \%$ dos alunos de administração responderam que ainda não tiveram aulas experimentais que Ihes permitissem responder ao questionamento; 38\% dos alunos de Agricultura e 34\% dos alunos de Administração relataram que as aulas práticas contribuíram bastante para um melhor entendimento do assunto abordado. A utilização de aulas práticas aliadas à abordagem expositiva é uma ideia defendida por vários profissionais da educação, admitindo-se a sua importância no esclarecimento de conceitos complexos que são difíceis de serem compreendidos apenas com a teoria (ARRUDA, 1996; OLIVEIRA et al., 2018).

Quando perguntados sobre a importância dos cistos da espécie Artemia salina, microcrustáceo utilizado na aula experimental, estarem submetidos à água do mar artificial com oxigênio abundante, cerca de $16 \%$ dos alunos de Agricultura e $28 \%$ dos alunos de Administração responderam que isso se justificava para que ficassem bastante hidratados; $6 \%$ dos estudantes da turma de Agricultura e $22 \%$ dos alunos de Administração responderam que isso se justificava para que ocorresse a descapsulação, promovendo, assim, o nascimento das larvas; $24 \%$ dos alunos de Agricultura e $18 \%$ dos alunos de Administração responderam que isso se justificava para criar uma resistência ao agente tóxico.

Ao serem questionados sobre o que poderia acontecer no ambiente se, em determinado local, tivesse sido encontrado um grande número de organismos mortos por pesticidas, $20 \%$ dos alunos de Agricultura e $28 \%$ dos alunos de Administração responderam que causaria intoxicação em diversos níveis da cadeia alimentar, $18 \%$ dos alunos da agricultura e $24 \%$ dos alunos da administração responderam que poderia causar doenças graves, e apenas $8 \%$ dos alunos do curso de agricultara e $2 \%$ dos alunos do curso de administração responderam que os pesticidas não prejudicariam os organismos aquáticos.

Quando perguntado quais os danos que podem ocorrer no ambiente aquático com a presença elevada de substâncias químicas na água, $4 \%$ dos alunos de Agricultura e 12\% dos alunos de Administração responderam que isso elevaria o nível do mar, $42 \%$ dos alunos de Agricultura e $42 \%$ dos alunos de Administração responderam que ocasionaria a mortalidade de espécies.

Também foi questionado se os organismos aquáticos estão sujeitos à intoxicação pela presença de poluentes na água, diante disso, 34\% dos alunos de Agricultura e 38\% dos alunos de Administração 


\section{sala \\ de $\oplus$ em \\ aula foco}

responderam que sim, 2\% dos alunos de Agricultura e 10\% dos alunos de Administração responderam que não. Ao serem indagados sobre os organismos sensíveis à presença de substâncias químicas no ambiente e se esses organismos poderiam ser úteis às ciências ambientais, 32\% dos alunos de agricultura e 32\% dos alunos da administração responderam que sim, 14\% dos alunos de agricultura e $22 \%$ dos alunos da administração responderam que não.

\subsection{Resultados de avaliação de aprendizagem pós-realização de aula prática}

Os resultados obtidos após a aula prática foram tabulados e comparados com aqueles obtidos antes da realização da aula prática. De acordo com os resultados apresentados na (Figura 01), pode-se perceber que, previamente à realização da aula prática, para as duas turmas, houve uma grande preferência por esta estratégia didática, mesmo antes do experimento ocorrer. Já a turma de administração, pósteste, apresentou resultado superior a $86 \%$ de preferência por aula prática, após a realização da mesma. Portanto, o resultado demonstra a necessidade de utilização de aulas práticas no ensino de Ciências ou Biologia, corroborando o que destaca Cardoso (2013, p.16) "a experimentação exerce um papel fundamental na aprendizagem dos alunos, pois possibilita a melhor compreensão dos seus conteúdos".

\section{Figura 01: Comparativo das respostas dos estudantes antes e após a realização da estratégia de ensino envolvendo atividades práticas.}

Turma de Agricultura pré-teste

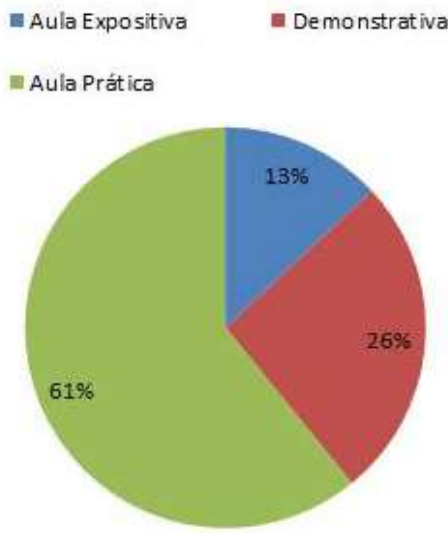

Turma Administração pré-teste

Turma de administrção com a prática
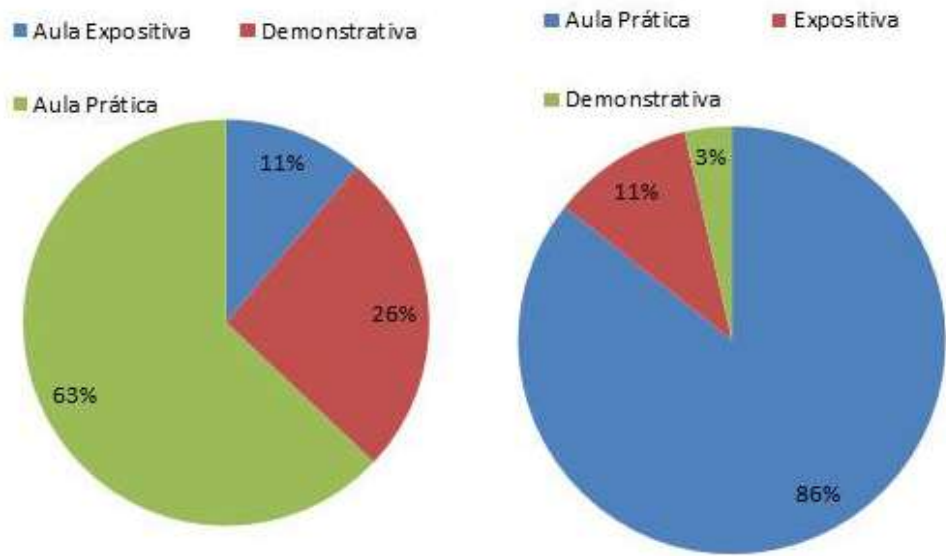

Fonte: Autor 


\section{sala \\ de $\oplus$ em \\ aula foco}

- REVISTA ELETRÔNICA

ISSN 2316-7297

Em outra questão, buscou-se analisar se ocorre a adoção de aulas práticas pelos professores das turmas ora analisadas, e observou-se no pré-teste que raramente os professores utilizam essas aulas. Perini et al. (2016), relatam essa realidade, visto que a maioria dos professores ainda utilizam métodos tradicionais de ensino e dificultam sua prática realizando aulas meramente teóricas. Em outra questão, em que se avaliou a relevância das aulas práticas para a construção do conhecimento, foi observado nas turmas pré-teste que ambas concordaram que as aulas em laboratório são importantes para o processo de ensino-aprendizagem); já na turma pós-teste o resultado foi superior ao previamente obtido, visto que os alunos tiveram maior contato com a experimentação). Bombonato (2011, p.11) refere-se às aulas práticas em laboratório como sendo importantes, pois, "despertam no estudante a curiosidade ou a vivência direta com metodologia científica". Ou seja, é um método de ensino capaz de incentivar o aluno na busca pelo conhecimento, de modo a fazer com que ele interaja com os colegas e professores na construção do saber.

Outra indagação foi com relação aos conteúdos, de modo a se estabelecer quais conteúdos os alunos acreditavam que aprenderiam melhor com a utilização de aulas práticas. As turmas pré-teste elencaram os seguintes temas: citologia, plantas, doenças, bioquímica, corpo humano, seres vivos, genética e ácidos nucléicos; já na turma pós-teste, os estudantes optaram por: genética, algas, corpo humano e plantas. De acordo com esse resultado, pode-se inferir que os conteúdos citados no pré-teste foram elencados aleatoriamente, enquanto os citados no pós-teste foram os conteúdos vistos pelos alunos como sendo os mais difíceis de compreender apenas com aulas teóricas. Prigol e Giannotti (2008, p.4) ressaltam que "a disciplina de Ciências Naturais é uma disciplina na qual a prática não deveria ser desvinculada da teoria. Por isso, acredita-se que o reconhecimento por parte dos alunos na construção do pensamento científico atesta o caráter investigativo das aulas práticas". Nesse sentido, observa-se que as aulas práticas serão importantes em qualquer outra disciplina, uma vez que levarão o aluno ao conhecimento científico por meio da investigação prática. Silva e Landim (2012, p. 3) refletem que "a utilização de aulas práticas associadas às aulas teóricas no ensino de Biologia é essencial para um mais efetivo aprendizado por parte dos alunos". Desta forma, faz-se necessário que o professor faça uso contínuo dessa modalidade de ensino visto que é muito proveitoso para o aluno.

Outras questões visavam analisar como as aulas práticas podem contribuir para o processo de ensino e aprendizagem de Biologia. Nesse sentido, $87 \%$ dos alunos do curso de Agricultura concordaram 


\section{sala \\ de $\oplus$ em \\ aula foco}

-REVISTA ELETRÔNICA

que conseguiram compreender melhor um assunto após a realização de uma aula experimental. Da mesma forma, a turma de Administração também destacou que obtém melhor compreensão após aula prática (92\%). Já após a realização de uma aula prática (pós-teste), o resultado foi ainda superior, demonstrando que 100\% acreditam que as aulas práticas contribuam mais para o aprendizado. Também buscou-se analisar como a carência dessas aulas práticas poderia comprometer o processo de ensino-aprendizagem, desta forma foi observado que $74 \%$ dos alunos de Agricultura concordaram que a falta dessas aulas práticas afetará, ao menos parcialmente, o processo de aprendizagem. Da mesma forma, a turma de Administração (63\%) acredita que a ausência dessas aulas práticas afetará, ao menos parcialmente, o processo de aprendizagem. As atividades práticas auxiliam na aprendizagem, ajudam a ampliar ideias e auxiliam na manutenção do interesse dos alunos, além de instigar habilidades como: a capacidade de resolver problemas e incentivar o instinto investigativo.

A função do uso das técnicas práticas, no âmbito da aprendizagem, é exatamente a coleta e a sistematização de informações, ou seja, é exercitando a técnica que se obtém consciência das dificuldades, probabilidades e limitações. Em termos cognitivos, a prática ajuda a tornar os conhecimentos mais próximos da realidade do aluno. Além disso, ajuda a organizar o mundo real e dar-Ihe mais exatidão, reduzindo as subjetividades, o que é necessário para que o conhecimento seja compreendido e compartilhado (VENTURI, 2012).

Outra questão verificou como a aula experimental, da qual os alunos participaram, contribuiu para o aprendizado dos mesmos. Os dados mostraram que cerca de $83 \%$ dos estudantes de Agricultura acreditam que essas aulas contribuíram bastante para a compreensão dos conteúdos vistos em sala de aula, resultado semelhante ao observado na turma de Administração, em que grande parte dos alunos (93\%) passou a acreditar na contribuição de atividades experimentais para o aprendizado, após sua experiência prática no laboratório.

Especificamente quanto ao conteúdo da aula prática, questionou-se os alunos sobre qual era a importância de os cistos estarem colocados em água do mar artificial e do oxigênio abundante. Após a realização da aula (pós-teste), os alunos responderam com mais acurácia a relevância do ambiente para a eclosão dos crustáceos. Em outra questão avaliou-se o conhecimento dos alunos sobre o que poderia ter acontecido no ambiente onde teria sido encontrado um grande número de 


\section{sala \\ de $\oplus$ em \\ aula foco}

organismos mortos por pesticidas. Após a realização da aula prática, reforçou-se que os pesticidas teriam provocado a intoxicação de diversos níveis na cadeia alimentar, de modo a causar grandes danos a um sistema biológico, alterando seriamente seu desenvolvimento ou levando-o à morte, sob certas condições de exposição.

A propriedade de agentes tóxicos de promoverem injúrias às estruturas biológicas, através de interações físico-químicas é chamada toxicidade. Portanto, a toxicidade é a capacidade inerente e potencial do agente tóxico de provocar efeitos nocivos em organismos vivos, sendo sua ação tóxica a maneira pela qual um agente tóxico exerce sua atividade sobre as estruturas teciduais (SEIZI, 1996, p. 5).

Outra questão buscou investigar se os alunos modificaram sua compreensão, pós-teste, sobre se organismos aquáticos estão sujeitos à intoxicação por poluentes na água. Nesse sentido, ambas as turmas concordaram (Figura 02) que esses organismos podem ser contaminados, visto que o uso inadequado de tais substâncias pode ocasionar a mortalidade de muitos organismos.

De acordo com Arias e colaboradores (2007), a biota aquática está firmemente exposta a um número grande de compostos tóxicos lançados no ambiente, originárias de diversas fontes de emissão. A descarga de lixos tóxicos naturais de efluentes industriais, os processos de drenagem agrícola, os derrames acidentais de lixos químicos e os esgotos domésticos espalhados em rios e mares colaboram para a contaminação dos ecossistemas aquáticos com uma ampla gama de agentes tóxicos como metais pesados, agrotóxicos, compostos orgânicos, entre outros.

Figura 02: Contribuição da aula prática para a sedimentação de conceitos, conforme observado pelo questionamento acerca da intoxicação dos organismos.
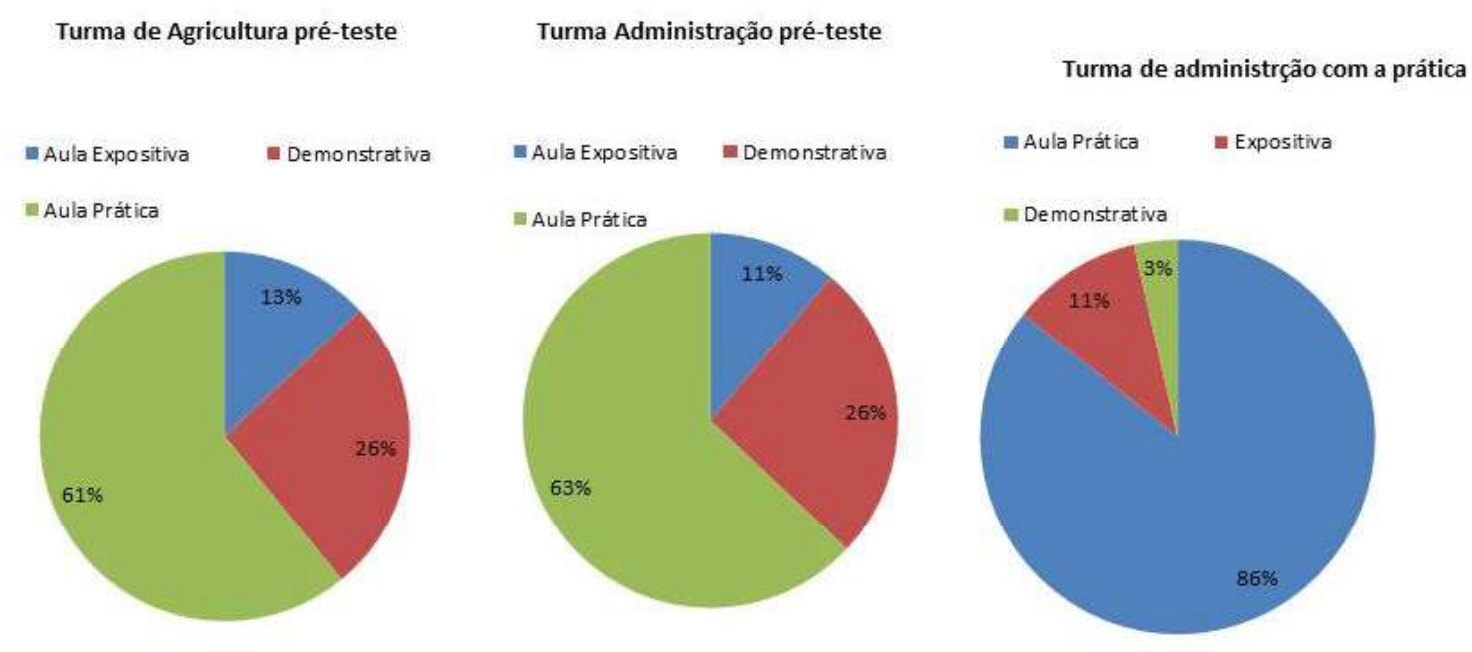

Fonte: Autor

Revista Eletrônica Sala de Aula em Foco, ISSN 2316-7297 - Volume 09, Número 01, 144-157, 2020 


\section{sala \\ de $\oplus$ em \\ aula foco}

-REVISTA ELETRÔNICA

Quando questionados sobre a sensibilidade à presença de substâncias químicas no ambiente, no pós-teste da turma de Administração 68\% acreditam que isto poderia ser útil às Ciências Ambientais. Quando questionados sobre os danos que poderiam acontecer no ambiente aquático se este apresentasse uma elevada quantidade de substancias químicas, observou-se que, no pós-teste, a turma de Administração (100\%) acredita que isso poderia causar sérios danos ao meio ambiente.

\section{CONSIDERAÇÕES FINAIS}

Quando trabalhada adequadamente, a experimentação se torna uma estratégia importante e aliada indispensável para o ensino, pois as experiências aproximam os alunos dos conteúdos, despertandoos também para a descoberta do conhecimento científico. E isso porque a atividade prática de laboratório aguça a curiosidade dos alunos despertando-os para mais questionamentos sobre os conteúdos e estimulando-os na busca por respostas que expliquem os fenômenos estudados.

Sabe-se que, na grande maioria dos espaços escolares, a realização de aulas práticas torna-se dificultada por fatores como a falta de infraestrutura, a carga horária de trabalho dos professores, entre outros. Entretanto, foi possível perceber que deixar de realizá-las pode comprometer a compreensão de determinados conteúdos, principalmente aqueles nos quais os alunos apresentam maior dificuldade. Nesse sentido, com a aplicação da metodologia prática em aula de Biologia confirmou-se que os alunos detêm grande preferência por essa abordagem pedagógica, em que boa parte dos discentes afirmaram que aprendem, de foram mais satisfatória, com as aulas práticas e que estas contribuem para a melhor compreensão dos conteúdos se trabalhadas em consonância com as aulas expositivas e demonstrativas. Com isso, o uso de bioensaios em aulas de Biologia no ensino médio pode constituirse em uma estratégia eficaz para a abordagem de múltiplos conteúdos, contribuindo diretamente com o aprendizado dos alunos.

\section{REFERÊNCIAS}

ANDRADE, T. Y. I.; ZANON, D. A. V.; SANTOS, A. R.; CECILIO, N. G.; ALBA, M. S. S.; REIS, L. A. D. Alimentação saudável em foco: oficina temática como estratégia para promover a aprendizagem significativa no Ensino de Ciências. Ciências \& Cognição, v. 23, n. 1, 2018.

ARIAS, A. R. L.; BUSS, D. F.; ALBURQUERQUE, C.; INÁCIO, A. F.; FREIRE, M. M.; EGLER, M.; MUGNAI, R.; BAPTISTA, D. F. Utilização de bioindicadores na avaliação de impacto e no monitoramento da 


\section{sala \\ de $\oplus$ em \\ aula foco}

REVISTA ELETRÔNICA

contaminação de rios e córregos por agrotóxicos. Ciência \& Saúde Coletiva, v. 12, n. 1, p. 61-72, 2007.

ARRUDA, S. M; LABURÚ, C. E. Considerações sobre a função do experimento no ensino de Ciências.

Pesquisa em Ensino de Ciências e Matemáticas, 1996.

BOMBANATO, L. G. G. A importância do uso do laboratório nas aulas de ciências. Monografia Universidade Tecnológica Federal do Paraná - UTFPR - Campus Medianeira, 2011.

BORTOLUZZI, L. Z.; COUTINHO, R. X. ATIVIDADES PRÁTICAS NO ENSINO DE BIOLOGIA PARA O PROEJA. Revista EJA em Debate, v. 7, n. 11, 2018.

CARDOSO, F. D. S. O uso de atividades práticas no ensino de ciências: Na busca de melhores resultados no processo ensino aprendizagem. Monografia - Centro Universitário Univates, 2013.

CHASSOT, A. Alfabetização científica: uma possibilidade para a inclusão social. Associação Nacional de Pós-Graduação e Pesquisa em Educação, 2003.

FREIRE, P. PEDAGOGIA DO OPRIMIDO. 59 ed. Rio de Janeiro: Paz e Terra, 2015. p. 107-166.

GALIAZZI, M. C.; ROCHA, J. M. B.; SCHMITZ, L. C.; SOUZA, M. L.; GIESTA, S.; GONÇALVEZ, F. P. Objetivos das Atividades Experimentais no Ensino Médio: A pesquisa coletiva como modo de formação de professores de ciências. Ciência \& Educação, v.7, n.2, 2001.

KRASILCHIK, M. Prática de ensino de biologia. São Paulo: Editora da Universidade de São Paulo, 2004.

LEAL, A. A.; MENDES SOBRINHO, J. A. C. A Experimentação nas Aulas de Ciências da 8a Série do Ensino Fundamental de Escolas Municipais de Teresina. In: MENDES SOBRINHO, J. A. C. Práticas Pedagógicas em Ciências Naturais: Abordagens na Escola Fundamental. Teresina: EDUFPI, 2008. p. 126-131.

MACHADO, L. F. R.; GOMES, M. F.; SANTOS, G. A. A importância da experimentação em química nas aulas de ciências naturais no ensino fundamental: um estudo com os alunos de $8^{\circ}$ e $9^{\circ}$ ano de uma escola de Orizona-GO. Multi-Science Journal, v. 1, n. 13, p. 09-14, 2018.

OLIVEIRA, A. K.; GARCIA, E. G. M.; MENEZES, E. G.; PERSICH, G. D. O. A Experimentação no Ensino Científico: Acompanhando o Crescimento de Feijões. In: GUNZEL, R. E.; GULLICH, R. I. C. Aprendendo ciências: ensino e extensão. Bagé: Faith, 2018. p. 12-14.

ORNELLAS, J. F. Interação Verbal e atividade prática experimental investigativa: dimensões para repensar a formação inicial de professores de química. Nuances: Estudos sobre Educação, v. 1, n. 25, 2013.

PIRES, M. R.; PEIXOTO, P. G.; OLIVEIRA, R. V. Fermentação alcoólica: proposta do ensino das vias bioquímicas através da destilação fracionada. Eclética Química, v. 40, p. 166-172, 2015. 


\section{sala \\ de $\oplus$ - em \\ aula foco}

PERINI, V.; OLIVEIRA, C. M.; CARNEIRO, M. A. M.; SANTOS, C. C. Os desafios da inserção de aulas práticas na rotina de uma escola pública: reflexões a partir de um estudo de caso. Revista da SBEnBio, n. 9, 2016.

PRIGOL, S.; GIANNOTTI, S. M. A Importância Da Utilização De Práticas No Processo De EnsinoAprendizagem De Ciências Naturais Enfocando A Morfologia Da Flor. In. 1o Simpósio nacional de educação 20으 semana da pedagogia. Cascavel. Anais... Cascavel: 2008. p.4.

SANTOS, C. M.; COLOMBO JÚNIOR, P. D. INTERDISCIPLINARIDADE E EDUCAÇÃO: DESAFIOS E POSSIBILIDADES FRENTE A PRODUÇÃO DO CONHECIMENTO. Revista Triângulo, 2018. Disponível em: <http://seer.uftm.edu.br/revistaeletronica/index.php/revistatriangulo/article/view/2672>. Acesso em: 11 ago 2018.

VENTURI, L. A. B. O Uso De Técnicas e Práticas No Ensino aprendizagem e Suas Contribuições No Processo De Formação. Entre-Lugar, v. 3, n. 6, p. 141-152, 2012.

SILVA, T. S; LANDIM, M. F. Aulas práticas no ensino de biologia: análise da sua utilização em escolas no município de lagarto/Se. In: VI COLÓQUIO INTERNACIONAL “EDUCAÇÃO E CONTEMPORANEIDADE", 6., 2012, Sergipe. Anais...Sergipe: 2012. p.3.

SEIZI, Oga. Fundamentos De Toxicologia. São Paulo: Atheneu, 1996. 